\title{
THE BEHAVIOR OF ION-IMPLANTED HYDROGEN IN GALLIUM NITRIDE
}

\author{
S. M. Myers, T.J. Headley, C.R. Hills, J. Han, G.A. Petersen, C.H. Seager, W.R. Wampler
}

Sandia National Laboratories, Albuquerque, NM 87185-1056, smmyers@ sandia.gov

\section{Cite this article as: MRS Internet J. Nitride Semicond. Res. 4S1, G5.8 (1999)}

\begin{abstract}
Hydrogen was ion-implanted into wurtzite-phase GaN, and its transport, bound states, and microstructural effects during annealing up to $980^{\circ} \mathrm{C}$ were investigated by nuclear-reaction profiling, ion-channeling analysis, transmission electron microscopy, and infrared (IR) vibrational spectroscopy. At implanted concentrations $\vee 1$ at.\%, faceted $\mathrm{H}_{2}$ bubbles formed, enabling identification of energetically preferred surfaces, examination of passivating N-H states on these surfaces, and determination of the diffusivity-solubility product of the H. Additionally, the formation and evolution of point and extended defects arising from implantation and bubble formation were characterized. At implanted $\mathrm{H}$ concentrations $\wedge 0.1$ at. $\%$, bubble formation was not observed, and ion-channeling analysis indicated a defect-related $\mathrm{H}$ site located within the [0001] channel.
\end{abstract}

\section{INTRODUCTION}

We investigated the transport, bound states, and microstructural effects of ion-implanted $\mathrm{H}$ in GaN. This work was undertaken for two reasons: first, the behavior of the implanted system provides information on a range of fundamental atomic processes involving $\mathrm{H}$ and defects; in addition, $\mathrm{H}$ implantation may ultimately be used in device processing for purposes such as electrical isolation and controlled separation of layers. This work builds upon several prior studies of implanted $\mathrm{H}$ in $\mathrm{GaN}$ [1-3].

Our experiments examined nominally undoped, wurtzite-phase GaN grown on sapphire by metal-organic chemical vapor deposition (MOCVD). The implanted concentrations of $\mathrm{H}$ ranged from hundredths of an atomic percent to several at.\% and spanned two regimes of behavior distinguished by the absence or presence of $\mathrm{H}_{2}$ bubbles. Atomic processes and microstructural evolution were investigated at temperatures up to $980^{\circ} \mathrm{C}$ using nuclear-reaction profiling of the $\mathrm{H}$, ion-channeling analysis of defects and $\mathrm{H}$ lattice location, transmission electron microscopy (TEM), and infrared (IR) spectroscopy of the local vibrational modes of the H. More thorough descriptions of the ion-channeling analyses and IR spectroscopy appear elsewhere $[4,5]$.

\section{EXPERIMENTAL PROCEDURE}

The MOCVD GaN films were grown with (0001) orientation and thicknesses in the range 1.4-2.3 $\mu \mathrm{m}$ as discussed elsewhere [6]. The nominally undoped material was of n-type with a free-carrier density of $\sim 10^{17} \mathrm{~cm}^{-3}$ as determined by conductivity and Hall-effect measurements. Hydrogen was ion-implanted into these films at room temperature in a turbomolecular-pumped vacuum of $\sim 10^{-7}$ Torr. Subsequent vacuum annealing was carried out in a quartz furnace tube that was continuously ion-pumped to a pressure of $\sim 10^{-7}$ Torr. 
Experiments involving nuclear-reaction analysis (NRA) of $\mathrm{H}$ employed the deuterium isotope $\left({ }^{2} \mathrm{H}\right)$, which was detected by counting protons from the ${ }^{3} \mathrm{He}$-induced reaction ${ }^{2} \mathrm{H}\left({ }^{3} \mathrm{He}, \mathrm{p}\right){ }^{4} \mathrm{He}$ using a Si surface-barrier detector. As a result of the energy dependence of the reaction cross section [7] and the continuous slowing of the ${ }^{3} \mathrm{He}$ particles within the target, the proton yield was affected by the depth distribution of the ${ }^{2} \mathrm{H}$ as well as by its quantity, and ${ }^{2} \mathrm{H}$ concentration versus depth could be obtained by measuring proton yield versus incident ${ }^{3} \mathrm{He}$ energy and performing a deconvolution [8]. Ion-channeling analysis of ${ }^{2} \mathrm{H}$ lattice location was carried out using the same nuclear reaction with the specimen manipulated in a 3-axis goniometer. The thickness of the GaN films was monitored by Rutherford backscattering spectrometry (RBS) with $1.7-\mathrm{MeV}^{1} \mathrm{H}$ to determine when annealing produced significant loss of material. Ion-channeling analysis of defects was performed using RBS with 2-MeV ${ }^{4} \mathrm{He}$. All of the channeling analyses were axial, with rotational averaging about the axis to avoid planar channeling.

Infrared vibrational spectroscopy was carried out using the ${ }^{1} \mathrm{H}$ and ${ }^{2} \mathrm{H}$ isotopes with multiple implanted layers being introduced to increase signal strength. These measurements were made at room temperature with a resolution of $4 \mathrm{~cm}^{-1}$. Samples for TEM were prepared by ion-thinning and were observed at an electron energy of $300 \mathrm{keV}$.

\section{RESULTS AND INTERPRETATION}

\section{Hydrogen Release During Isochronal Annealing}

The retention of implanted ${ }^{2} \mathrm{H}$ within GaN was monitored by NRA during a sequence of 1-hour vacuum anneals at temperatures incremented by $\sim 100^{\circ} \mathrm{C}$. These experiments were carried out on specimens that had been implanted with $10^{15}, 10^{16}$ or $10^{172} \mathrm{H} / \mathrm{cm}^{2}$ at room temperature and $50 \mathrm{keV}$ to produce the calculated [9] depth profiles shown in Fig. 1. The NRA was performed with an incident ${ }^{3} \mathrm{He}$ energy of $0.85 \mathrm{MeV}$, which, using published results for the nuclear cross section [7] and He stopping powers [10], is calculated to result in the depthdependent differential cross section shown in Fig. 1. The nuclear-reaction yield under these conditions provides a quantitative measure of the amount of ${ }^{2} \mathrm{H}$ remaining within the implanted region.

Results from these experiments are presented in Fig. 2, where the retained fraction of ${ }^{2} \mathrm{H}$ is plotted versus temperature. The anneal at the highest temperature, $980^{\circ} \mathrm{C}$, produced significant loss of material from the $\mathrm{GaN}$ film as observed by RBS, so that the corresponding datum does not provide a quantitative measure of ${ }^{2} \mathrm{H}$ release by diffusion. In the case of the lowest implantation dose, effects of the analysis beam on the release were observed, so each measurement was

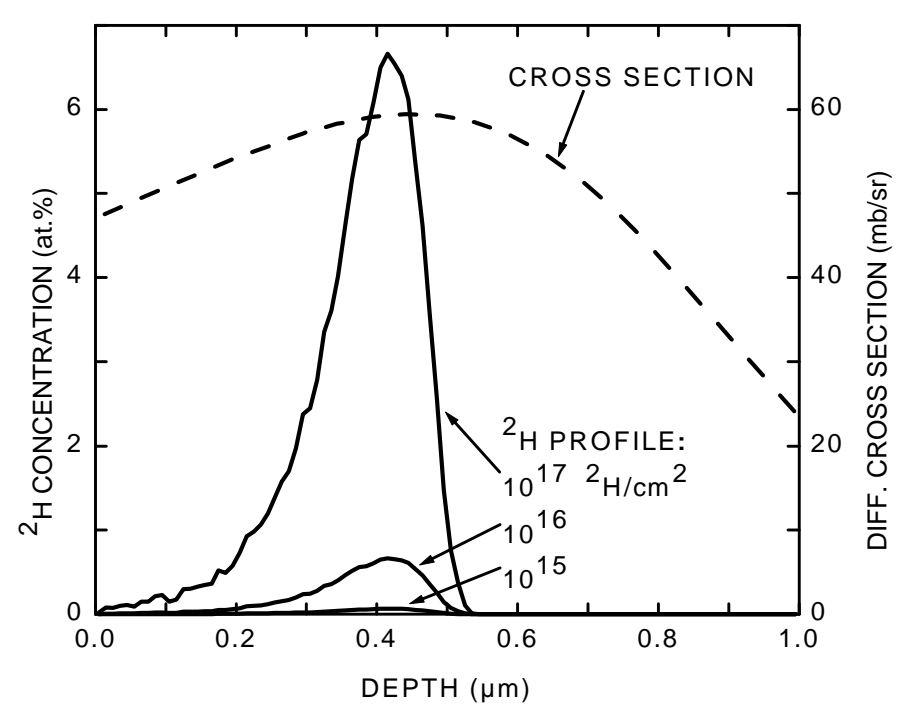

Fig. 1. Calculated depth profiles of implanted ${ }^{2} \mathrm{H}$ and the differential nuclear cross section for $0.85-\mathrm{MeV}^{3} \mathrm{He}$ with a scattering angle of $135^{\circ}$. 
made at a new location on the specimen.

For all three doses, the ${ }^{2} \mathrm{H}$ remained localized in the implanted region during the release rather than assuming a diffusion-broadened profile. This is seen from the representative concentrationversus-depth profile in Fig. 3, which was measured in the sample implanted with $10^{17} \mathrm{H} / \mathrm{cm}^{2}$ after the anneal sequence had reached $886^{\circ} \mathrm{C}$ and about $2 / 3$ of the ${ }^{2} \mathrm{H}$ had been lost. This profile was obtained by measuring the proton yield from the nuclear reaction as a function of incident ${ }^{3} \mathrm{He}$ energy and performing a deconvolution [8], giving a distribution represented by contiguous straight-line

segments. The depth resolution of this method is about $0.2 \mu \mathrm{m}$ for $\mathrm{GaN}$, which suffices to exhibit the property of interest.

The release of ${ }^{2} \mathrm{H}$ is seen from Fig. 2 to occur in approximately the same temperature range for implanted concentration from hundredths of an atomic percent to several at.\%, notwithstanding fundamental differences in the state of the ${ }^{2} \mathrm{H}$ at the lower and higher concentrations that are discussed below. For the lowest dose, the temperature range of release is consistent with earlier work where $\mathrm{H}$ was implanted to comparable concentrations in undoped material $[1,3]$. The absence of diffusion broadening of the implanted peak during the release indicates that the $\mathrm{H}$ exists predominantly in bound states rather than being in mobile solution. The nature of these states is addressed in the remainder of this paper.

\section{$\mathrm{H}_{2}$ Bubble Formation with Wall Chemisorption of $\mathrm{H}$ at Implanted Concentrations $\vee 1$ at. $\%$}

When the implanted concentration of $\mathrm{H}$ was $\vee 1$ at. $\%, \mathrm{H}_{2}$ bubbles formed within the $\mathrm{GaN}$. After annealing in the temperature range of $\mathrm{H}$ release, TEM showed most of these bubbles to be polyhedra with a single (0001) facet and $6\{10 \overline{1} 1\}$ facets, a shape which reduces to a 6 -sided pyramid when the hexagonal basal-plane facet is equilateral. Representative high-resolution images in plan view and cross section are shown in Fig. 4. With no noted exceptions, the base of the polyhedral bubbles was toward the surface of the sample and the apex toward the sapphire substrate. Such an absence of inversion symmetry along [0001] indicates that the facets have a preferred polarity. The identification of this polarity requires determination of the polarity of the 

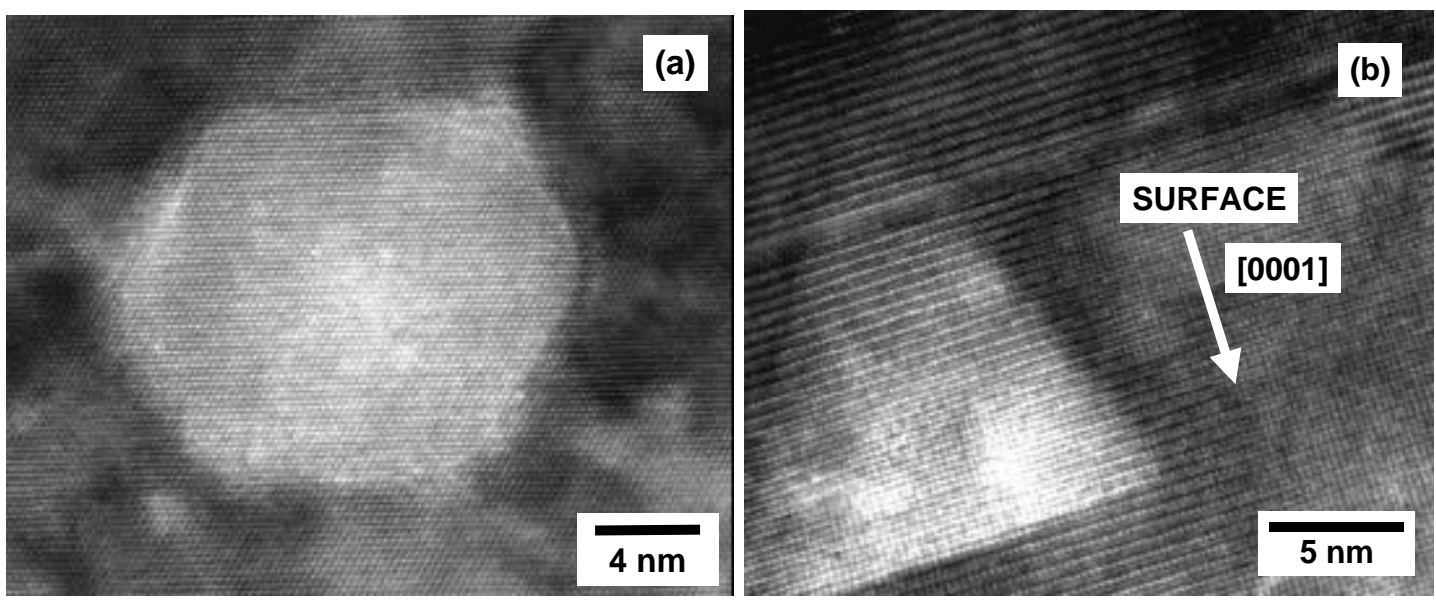

Fig. 4. High-resolution TEM images of bubbles in GaN: (a) plan-view in [0001] orientation and (b) cross-section in [1120] orientation. The implanted layer was injected with $2 \times 10^{16}{ }^{1} \mathrm{H} / \mathrm{cm}^{2}$ at room temperature, and the specimen was then annealed at $886^{\circ} \mathrm{C}$ for 1 hour.

epitaxial film. Although this is challenging, several groups have concluded on the basis of convergent-beam electron diffraction and other measurements that smooth MOCVD GaN on sapphire has $\mathrm{N}$ atoms above $\mathrm{Ga}$ atoms along [0001]-oriented bonds, or, equivalently, that the unreconstructed top surface of the film is terminated by Ga atoms [11-14]. This implies that the (0001) and $\{10 \overline{1} 1\}$ internal surfaces of the observed bubbles, both comprising close-packed Ga-N bilayers, have N-terminated polarity. Since the bubbles formed after growth, we conclude that these surfaces were energetically preferred.

In view of the relatively high reactivity of $\mathrm{N}$ and the transfer of electronic charge from $\mathrm{Ga}$ to $\mathrm{N}$ in $\mathrm{GaN}$, a preference for $\mathrm{N}$-terminated surfaces is surprising unless these surface are H-passivated. We obtained evidence for such passivation from IR vibrational spectroscopy, as discussed more fully elsewhere [5]. Under conditions of implantation where bubbles formed, but not otherwise, we observed new IR absorption peaks at 3182 and $3216 \mathrm{~cm}^{-1}$ for ${ }^{1} \mathrm{H}$, as shown in Fig. 5, and at 2364 and $2386 \mathrm{~cm}^{-1}$ for ${ }^{2} \mathrm{H}$. These absorptions are ascribed to N-H centers, based both on comparisons with materials known to contain $\mathrm{N}-\mathrm{H}$ and on the size of the departure of the isotope shift from $\sqrt{ } 2$. The frequencies lie above those reported when the concentration of implanted $\mathrm{H}$ is $\wedge 0.1$ at.\% [2], a regime where we did not observe bubble formation and the $\mathrm{H}$ is believed bound to defects. Moreover, the integrated strength of the absorptions in Fig. 5 corresponds to about $4 \%$ of the implanted $\mathrm{H}$ being in the IR-active state, and this is consistent with estimates of the number of chemisorption sites on the bubble

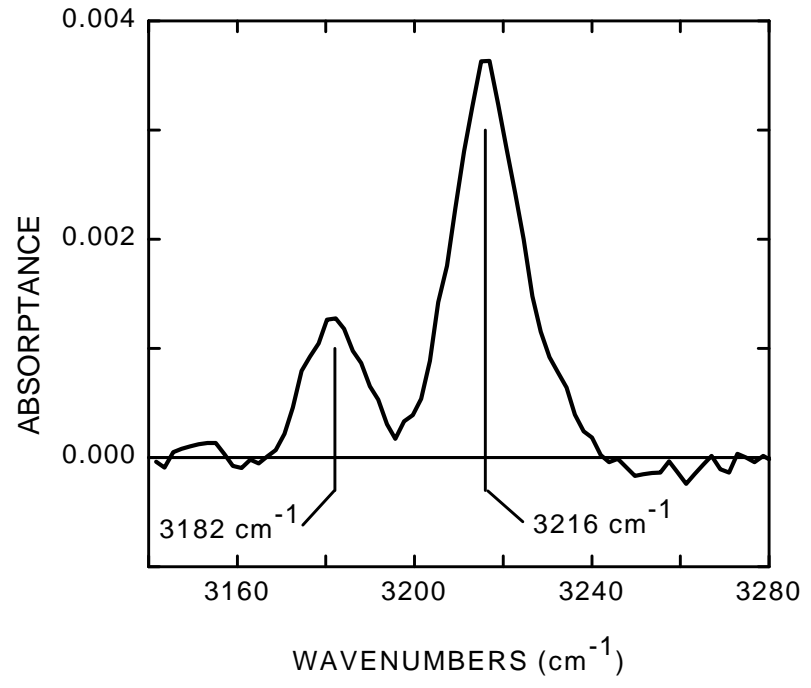

Fig. 5. Infrared absorption peaks ascribed to ${ }^{1} \mathrm{H}$ chemisorbed on bubble walls. The specimen was implanted with $2 \times 10^{16}{ }^{1} \mathrm{H} / \mathrm{cm}^{2}$ in each of 5 layers and then annealed at $600^{\circ} \mathrm{C}$ for 1 hour. 
walls. We consider these findings strongly indicative of $\mathrm{H}$ passivation of the bubble walls.

During isochronal annealing sequences similar to those of Fig. 2, the strength of the IR absorptions shown in Fig. 5 decreased before the total amount of ${ }^{2} \mathrm{H}$ measured by NRA. This is seen in Fig. 6 , where both quantities are plotted versus anneal temperature. We infer that the chemisorbed state is less stable than the molecular gas under the conditions of these experiments.

\section{Isothermal Release from Bubbles and the Diffusivity-Solubility Product of $\mathbf{H}$}

In order to characterize further the thermal release of $\mathrm{H}$ from $\mathrm{H}_{2}$ bubbles, we used NRA to measure the amount remaining during isothermal vacuum annealing at 794 and $886^{\circ} \mathrm{C}$. The specimens were implanted with $1 \times 10^{17}{ }^{2} \mathrm{H} / \mathrm{cm}^{2}$ at $50 \mathrm{keV}$, and the areal density of ${ }^{2} \mathrm{H}$ within the implanted layer was monitored using a ${ }^{3} \mathrm{He}$ energy of $0.85 \mathrm{MeV}$, replicating conditions depicted in Fig. 1. The results obtained at $886^{\circ} \mathrm{C}$ are presented in Fig. 7. Depth profiling at selected points in the sequence, using procedures described for Fig. 3, showed that the retained ${ }^{2} \mathrm{H}$ was always localized in the implanted layer rather than developing a diffusion-broadened distribution.

From the TEM observations

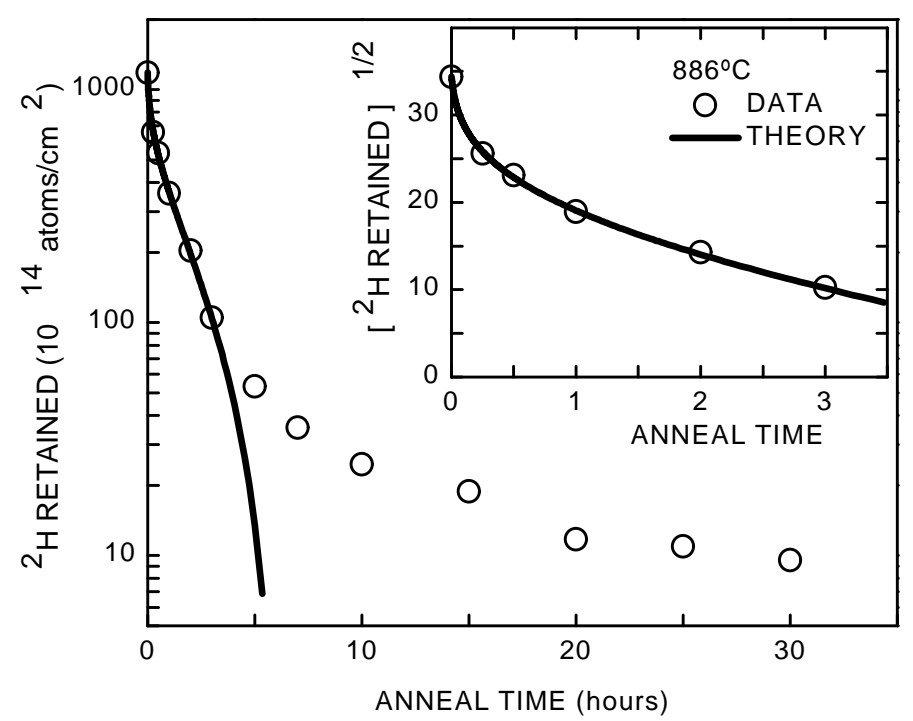

Fig. 7. Release of ion-implanted ${ }^{2} \mathrm{H}$ from $\mathrm{GaN}$ during isothermal annealing at $886^{\circ} \mathrm{C}$. discussed above, we conclude that the release shown in Fig. 7 was predominantly from $\mathrm{H}_{2}$ gas within bubbles. Furthermore, we assume, in accord with theoretical predictions [15], that the transport of the $\mathrm{H}$ through the matrix occurred by dissociation of the molecule followed by atomic diffusion. Then, using the approximation of steady-state diffusion, the variation with time of the retained areal density of $\mathrm{H}$ atoms, $\Lambda$, is given by

$$
(\mathrm{d} / \mathrm{dt}) \Lambda=-\mathrm{D} \mathrm{N}_{\mathrm{H} 0}\left(\mathrm{P}^{*} / \mathrm{P}_{0}\right)^{1 / 2} / \mathrm{X}
$$


where $\mathrm{D}$ is the effective diffusion coefficient, $\mathrm{N}_{\mathrm{H} 0}$ is the solubility of mobile $\mathrm{H}$ in local equilibrium with the $\mathrm{H}_{2}$ gas at some reference pressure $\mathrm{P}_{0}$ small enough for the gas to behave ideally, $\mathrm{P}^{*}$ is the fugacity of the $\mathrm{H}_{2}$ gas in the bubbles, and $\mathrm{X}$ is the diffusion distance to the surface, taken to be single-valued for simplicity. The fugacity can be defined in terms of the chemical potential and related through it to the equation of state:

$$
\ln \left(\mathrm{P}^{*} / \mathrm{P}_{0}\right) \equiv\left(\mu-\mu_{0}\right) / \mathrm{kT}=(\mathrm{kT})^{-1} \int_{\mathrm{P}_{0}}^{\mathrm{P}} \mathrm{V}\left(\mathrm{P}^{\prime}\right) \mathrm{dP}
$$

where $\mu_{0}$ is the chemical potential at the reference pressure and $\mathrm{V}(\mathrm{P})$ is the volume per $\mathrm{H}_{2}$ molecule at pressure $\mathrm{P}$ as given by the equation of state. At lower pressures where the ideal-gas equation of state is applicable, $\mathrm{P}^{*} \rightarrow \mathrm{P}$. In order to complete the description of the system, a relationship must be specified between $\mathrm{P}$ and $\Lambda$. This is accomplished by noting that

$$
\mathrm{V}(\mathrm{P})=2 \mathrm{~V}_{\mathrm{b}} / \Lambda
$$

where the function $\mathrm{V}(\mathrm{P})$ is given by the equation of state and $\mathrm{V}_{\mathrm{b}}$ is the combined bubble volume per unit sample area. Solution of Eqs. (1)-(3) shows that that $\Lambda^{1 / 2}$ decreases linearly with time at lower pressures where $\mathrm{V}(\mathrm{P})$ follows the ideal equation of state, while a more rapid initial transient is predicted if the starting pressure is high enough for the gas to behave non-ideally. Such behavior is evident in the inset of Fig. 7, where the initial part of the measured isotherm is plotted as $\Lambda^{1 / 2}$ versus t. The curve through the data represents a solution of Eqs. (1)-(3) in which the amplitude of the initial transient was fitted by adjusting $\mathrm{V}_{\mathrm{b}}$ or, equivalently, the initial bubble pressure $\mathrm{P}_{1}$, and the variation at longer times was fitted by adjusting the diffusivity-solubility product $\mathrm{D} \times \mathrm{N}_{\mathrm{H} 0}$ for $\mathrm{P}_{0}=1$ bar. In this way we obtained $\mathrm{P}_{1}=6 \mathrm{GPa}$ and $\mathrm{D} \times \mathrm{N}_{\mathrm{H} 0}=$ $2.2 \times 10^{6}$ atoms cm ${ }^{-1} \mathrm{~s}^{-1}$ for $\mathrm{T}=886^{\circ} \mathrm{C}$; the analogous experiment at $794^{\circ} \mathrm{C}$ yielded $\mathrm{P}_{1}=9 \mathrm{GPa}$ and $\mathrm{D} \times \mathrm{N}_{\mathrm{H} 0}=2.0 \times 10^{5}$ atoms $\mathrm{cm}^{-1} \mathrm{~s}^{-1}$.

It is apparent from the semilog plot in Fig. 7 that a small fraction of the implanted $\mathrm{H}$, $\sim 5 \%$, was released much more slowly than predicted by Eqs. (1)-(3). We consider two possible explanations for this. First, the residual $\mathrm{H}$ might conceivably exist in some bound state more stable than $\mathrm{H}_{2}$ gas within the bubbles. A difficulty, however, is that we did not find IR absorptions associated with the $\mathrm{H}$ retained to long times, nor did this $\mathrm{H}$ exhibit the channeling effects in NRA that would be expected for a unique atomic position relative to the host lattice; hence, the bound state in question apparently does not involve $\mathrm{N}-\mathrm{H}$ or $\mathrm{Ga}-\mathrm{H}$ bonding. If, alternatively, the strongly retained $\mathrm{H}$ is imagined to exist as $\mathrm{H}_{2}$ molecules, there is the problem of identifying a location where the molecules are more stably bound than the open volumes of the bubbles.

A second interpretation, and one which we currently consider more viable, is that the release takes place from $\mathrm{H}_{2}$ bubbles over the entire anneal sequence, but the diffusivity-solubility product $\mathrm{D} \times \mathrm{N}_{\mathrm{H} 0}$ decreases with time due to a shift in the Fermi level as the $\mathrm{H}$ concentration in solution decreases. Theoretical calculations reported for the cubic, zincblende variant of $\mathrm{GaN}$ [15] and a recent treatment of the hexagonal, wurtzite phase [16] both indicate that dissociated $\mathrm{H}$ in solution exists predominantly as $\mathrm{H}^{+}$or $\mathrm{H}^{-}$, depending upon the position of the Fermi level, with the neutral atom always being less stable. Additionally, the positive ion is predicted to be much more mobile than the negative ion. Our tentative interpretation of the release isotherm is then that, during $~ 95 \%$ of the release, the solution concentrations of $\mathrm{H}^{+}$and $\mathrm{H}^{-}$exceed the concentrations of other electrically active species, and as a result the Fermi level is stabilized at a position such that $\left[\mathrm{H}^{+}\right] \sim\left[\mathrm{H}^{-}\right]$, with $\mathrm{D} \times \mathrm{N}_{\mathrm{H} 0}$ being nearly constant as a result. In the last stages of the release, however, the $\mathrm{H}_{2}$ pressure in the bubbles, and hence the $\mathrm{H}$ chemical potential, decreases until the $\mathrm{H}$ concentration in the lattice is less than that of donors unrelated to $\mathrm{H}$; at this 
point, the Fermi level rises, reducing the fraction of mobile $\mathrm{H}^{+}$and increasing that of the lessmobile $\mathrm{H}^{-}$.

\section{Bubble-Related Defect Microstructure and Its Evolution with Temperature}

By using ion-channeling analysis in conjunction with TEM to characterize implantation-related defects, we elucidated the atomic processes associated with bubble formation and defect annealing. Figure 8 shows channeling results for a specimen that was implanted with $10^{17} \mathrm{H} / \mathrm{cm}^{2}$ at $50 \mathrm{keV}$ and room temperature and then subjected to a series of 1hour vacuum anneals at increasing temperature. The exhibited RBS spectra were produced by 2$\mathrm{MeV}{ }^{4} \mathrm{He}$ incident along the [0001] axis with the sample at room temperature, and an unchanneled, or random, spectrum is included for reference. Backscattering yield from the implanted region appears at channels in the range 90-120, while the surface corresponds approximately to channel 140 .

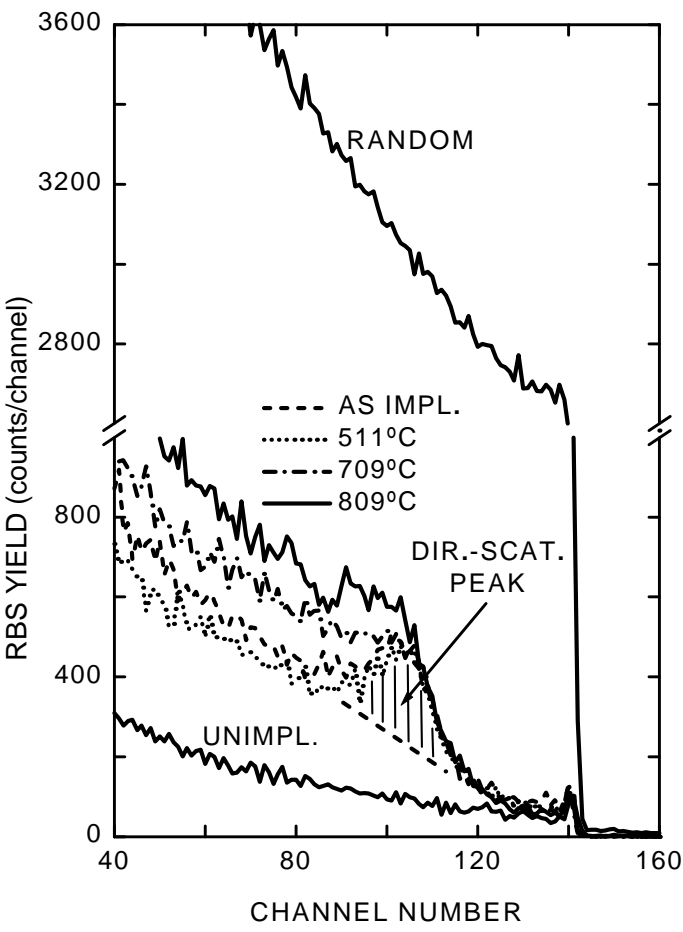

Fig. 8. Channeled RBS spectra from GaN before and after ${ }^{2} \mathrm{H}$ implantation and annealing, obtained using $2-\mathrm{MeV}^{4} \mathrm{He}$.

A direct-scattering peak appears in the channeled spectrum after implantation and before annealing, as indicated in the figure. As discussed more fully elsewhere [4], the presence of this peak means that Ga atoms are removed from substitutional lattice sites into the open [0001] channel. Analysis of the area under the peak indicates that the areal density of Ga interstitials is $3.0 \times 10^{16} \mathrm{~cm}^{-2}$ [4]; this is equal within experimental uncertainty to the areal density of $\mathrm{Ga}$ atoms displaced by bubble formation, which we calculate from the known $\mathrm{H}$ areal density and $\mathrm{H}_{2}$ gas pressure to be $3.4 \times 10^{16} \mathrm{~cm}^{-2}$. This finding is consistent with the following model of bubble formation: the equally numerous vacancies and interstitials produced by collisional atomic displacements mostly undergo annihilation by recombination; however, a small fraction of the vacancies agglomerate and collect $\mathrm{H}$ to form high-pressure $\mathrm{H}_{2}$ bubbles, thereby constraining the recombination and leaving a corresponding number of interstitials within the lattice.

Annealing in the temperatures range $511-709^{\circ} \mathrm{C}$ is seen in Fig. 8 to remove the directscattering peak and introduce a dechanneling step. This indicates a return of $\mathrm{Ga}$ atoms to substitutionality, accompanied by the formation of extended defects with large strain fields to produce the observed dechanneling with relatively little direct scattering. Transmission electron microscopy after this evolution showed the predominant extended defect to be a (0001) stacking fault containing one extra Ga-N bilayer and bounded by a partial dislocation, a configuration discussed in detail elsewhere [17]. A part of one such stacking fault is seen in the highresolution cross-section TEM image of Fig. 9. Analysis of the amplitude of the dechanneling step gives the density of the stacking faults. The result indicates that only a small fraction of the Ga interstitials present before annealing, about 3\%, agglomerate in this way [4]; the remainder undergo annihilation, presumably by migrating to the surface of the film. 
Hydrogen Behavior in the Absence of Bubbles at Concentrations $\wedge 0.1$ at.\%

When GaN was implanted with $50-\mathrm{keV}^{2} \mathrm{H}$ at room temperature to a dose of $10^{15} \mathrm{~cm}^{-2}$, ionchanneling analysis revealed that a large fraction of the ${ }^{2} \mathrm{H}$ occupied a well-defined location relative to the host lattice. Figure 10 shows the nuclearreaction yield from the ${ }^{2} \mathrm{H}$ as a function of angle from the [0001] direction, with the elastic backscattering yield from Ga superimposed for comparison; these yields were produced by 0.85 $\mathrm{MeV}{ }^{3} \mathrm{He}$ and $2-\mathrm{MeV}{ }^{4} \mathrm{He}$, respectively. The detected $\mathrm{H}$ site is believed to be defect related, since the amplitude of the channeling peak rises markedly during initial impingement of the ${ }^{3} \mathrm{He}$ analysis beam, and rises more rapidly when that beam is tilted from the channeling orientation so that more atomic displacements are produced. Numerical simulations of the channeling indicate that the narrow peak in the nuclear-reaction yield can be produced only by ${ }^{2} \mathrm{H}$ that is displaced into the central region of the open [0001] channel [4]. During a succession of 1-hour anneals at increasing temperature, this peak remained essentially unchanged after $411^{\circ} \mathrm{C}$, but decreased in amplitude with increasing temperature from $511^{\circ} \mathrm{C}$ upward, becoming poorly resolved by $809^{\circ} \mathrm{C}$.

Previously, ${ }^{1} \mathrm{H}$ implanted to similar concentrations in $\mathrm{GaN}$ was found by IR spectroscopy to have local vibrational modes in the frequency range $2983-3150 \mathrm{~cm}^{-1}$ [2]. These modes were assigned with confidence to $\mathrm{N}-\mathrm{H}$ centers, which were plausibly hypothesized to be located in the Ga vacancy. The absorption spectrum evolved with increasing anneal temperature and disappeared at about $700^{\circ} \mathrm{C}$. The similarity with our experiments raises the possibility that the same $\mathrm{H}$ state was probed by the two techniques; this is not necessarily so, however, since the fraction of the implanted $\mathrm{H}$ contributing to the observed IR peaks may have been as small as $10 \%$ [18]. In any case, the Ga vacancy does not appear viable for the trap observed by channeling, since $\mathrm{H}$ tetrahedrally bonded to a neighboring $\mathrm{N}$ would not protrude into the [0001] channel. It therefore seems appropriate to consider other defects, including those of interstitial type, as possible binding sites.

Since the $\mathrm{H}$ state or states probed by the ion channeling and IR spectroscopy disappear after annealing at temperatures $\wedge 800^{\circ} \mathrm{C}$, these are apparently not the states from which the final release near $900^{\circ} \mathrm{C}$ occurs. The last state of the $\mathrm{H}$ is also believed not to involve bubbles or extended defects, since, in cross-section TEM of $\mathrm{GaN}$ implanted with $10^{15} \mathrm{H} / \mathrm{cm}^{2}$ at $50 \mathrm{keV}$ and then annealed at $886^{\circ} \mathrm{C}$ for 1 hour, we did not observe such microstructural features produced by the implantation. Conceivably, $\mathrm{H}_{2}$

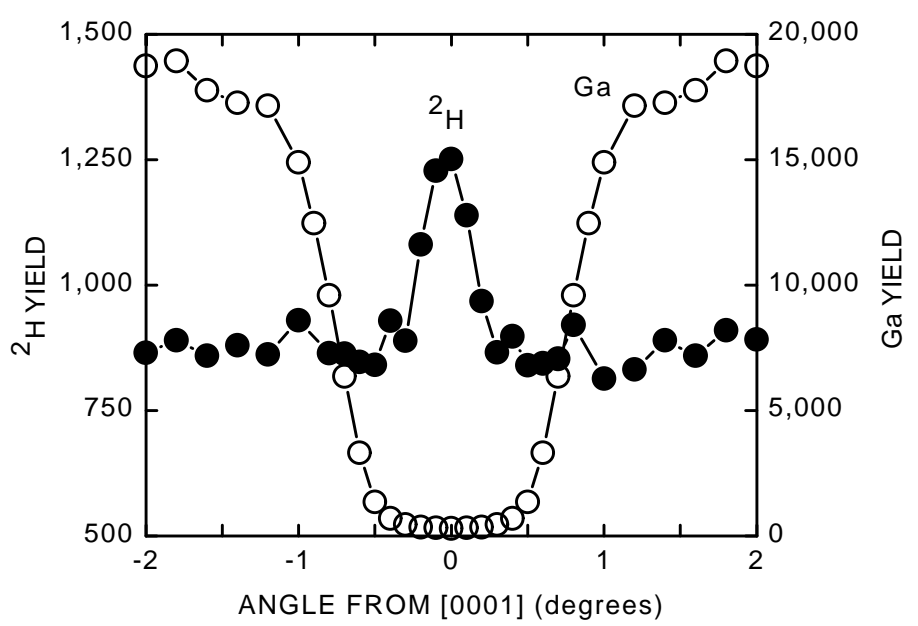

Fig. 10. Channeling scans after implanting $10^{15} \mathrm{H} / \mathrm{cm}^{2}$ into $\mathrm{GaN}$ at room temperature. 
forms within vacancy-type defects at the most elevated temperatures.

\section{SUMMARY}

We investigated the behavior of ion-implanted $\mathrm{H}$ in MOCVD GaN on sapphire at concentrations ranging from hundredths of an atomic percent to several at.\%. The results of these experiments were interpreted in terms of underlying physical processes, providing new information on fundamental aspects of $\mathrm{H}$ and defect behavior.

At implanted concentrations $\vee 1$ at. $\%$, faceted $\mathrm{H}_{2}$ bubbles formed with (0001) and $\{10 \overline{1} 1\}$ faces of $\mathrm{N}$-terminated polarity, indicating that such surfaces were energetically preferred. Infrared spectroscopy showed localized vibrational modes attributable to $\mathrm{N}-\mathrm{H}$ on the bubble walls at a coverage of $\sim 1$ monolayer. From this we concluded that the otherwise highly reactive $\mathrm{N}$-terminated surfaces were passivated by $\mathrm{H}$, and that the attendant large reduction in surface energy probably affected the observed selection of surfaces. During isochronal annealing, the $\mathrm{N}-\mathrm{H}$ state detected by IR spectroscopy diminished at somewhat lower temperatures than the total quantity of $\mathrm{H}$ measured by NRA, indicating that the chemisorbed state was less stable than the $\mathrm{H}_{2}$ gas.

Hydrogen was strongly retained within the bubbles, undergoing release only at temperatures $\vee 800^{\circ} \mathrm{C}$. By analyzing retention-versus-time isotherms, the pressure within the bubbles and the diffusivity-solubility product of the $\mathrm{H}$ were evaluated. We provisionally hypothesized that most of the release occurred with the Fermi level stabilized by ionized $\mathrm{H}$ atoms in solution in such a way that $\left[\mathrm{H}^{+}\right] \sim\left[\mathrm{H}^{-}\right]$.

Our examination of defects arising from the higher-dose implantations and attendant bubble formation led to several mechanistic inferences. The added volume of the bubbles is believed to be accommodated by the agglomeration of implantation-generated vacancies, and this leaves a corresponding number of host-atom interstitials within the lattice. These interstitial defects undergo substantial evolution in the approximate temperature range $500-700^{\circ} \mathrm{C}$; most are annihilated, presumably at the surface, with a small residual being incorporated into basal-plane stacking faults bounded by partial dislocations.

At implanted concentrations $\wedge 0.1$ at.\%, bubble formation was not observed, and the $\mathrm{H}$ was concluded from channeling analysis to occupy a defect-related interstitial site in the [0001] channel. Prior to thermal release from the specimen, the $\mathrm{H}$ apparently moves to a more stable state that is not characterized by a unique lattice sites and is not IR-active, conceivably $\mathrm{H}_{2}$ within vacancy defects.

\section{ACKNOWLEDGEMENTS}

The authors benefited greatly from interactions with D. M. Follstaedt, S. J. Pearton, M. J. Stavola, and A. F. Wright. The work was supported by the Office of Basic Energy Sciences, U. S. Dept. of Energy, under Contract DE-AC04-94AL85000. Sandia National Laboratories is a multiprogram laboratory operated by Sandia Corp., a Lockheed Martin Company, for the U. S. Dept. of Energy.

\section{REFERENCES}

1. J.M. Zavada, R.G. Wilson, C.R. Abernathy, and S.J. Pearton, Appl. Phys. Lett. 64, 2724 (1994). 
2. M.G. Weinstein, C.Y. Song, M. Stavola, S.J. Pearton, R.G. Wilson, R.J. Shul, K.P. Killeen, and M.J. Ludowise, Appl. Phys. Lett. 72, 1703 (1998).

3. S.J. Pearton, R.G. Wilson, J.M. Zavada, J. Han, and R.J. Shul, Appl. Phys. Lett. 73, 1877 (1998).

4. W.R. Wampler and S.M. Myers, MRS Internet J. Nitride Semicond. Res. 4S1, G3.73(1999).

5. C.H. Seager, S.M. Myers, G.A. Petersen, J. Han, and T.J. Headley, J. Appl. Phys., in press.

6. T.-B. Ng, J. Han, R.M. Biefeld, and M.V. Weckwerth, J. Electron. Mater. 27, 190 (1998).

7. W. Möller and F. Besenbacher, Nucl. Instrum. Meth. 168, 111 (1980).

8. S. M. Myers, G. R. Caskey, Jr., D. E. Rawl, Jr., and R. D. Sisson, Jr., Metall. Trans. A 14, 2261 (1983).

9. Ion ranges were calculated using the TRIM-90 Monte-Carlo code described by J. F. Ziegler, J. P. Biersack, and U. Littmark, The Stopping and Range of Ions in Solids (Pergamon, New York, 1985), and by J. F. Ziegler, 1990, unpublished.

10. J. F. Ziegler, Helium Stopping Powers and Ranges in All Elements (Pergamon, New York, 1977).

11. F. A. Ponce, D. P. Bour, W. T. Young, M. Saunders, and J. W. Steeds, Appl. Phys. Lett. 69, 337 (1996).

12. B. Daudin, J. L. Rouvière, and M. Arlery, Appl. Phys. Lett. 69, 2480 (1996).

13. M. Seelmann-Eggebert, J. L. Weyher, H. Obloh, H. Zimmermann, A. Rar, and S. Porowski, Appl. Phys. Lett. 71, 2635 (1997).

14. Z. Liliental-Weber, O. Richter, J. Washburn, K. Pakula, J. Baranowski, I. Grzegory, S. Porowski, and J. Y. Yang, reported at the 1998 Spring Meeting of the Materials Research Society.

15. J. Neugebauer and C. G. Van de Walle, Phys. Rev. Lett. 75, 4452 (1995).

16. A.F Wright, to be published.

17. Z. Liliental-Weber, C. Kisielowski, S. Ruvimov, Y. Chen, J. Washburn, I. Grzegory, M. Bockowski, J. Jun, and S. Porowski, J. Electron. Mater. 25, 1545 (1996).

18. M.J. Stavola, private communication. 